\title{
A new method to improve disaster response capacity of important loads in distribution network
}

\author{
Qin Lijun ${ }^{1,}$, Zhai Xiongfei ${ }^{2, b}$ \\ ${ }^{1}$ North China Electric Power University, Beijing, 102206, China \\ ${ }^{2}$ North China Electric Power University, Beijing, 102206, China \\ a, b email: zhaixiongfei0915@126.com
}

Keywords: distribution network; important loads; situation awareness; disaster response.

\begin{abstract}
This paper introduces the disaster response research status quo of important loads in distribution network, summed up the research and practice results at home and abroad. The focus of this paper is proposed the concept of situation awareness. Through carrying out situation awareness in distribution network, improve the disaster warning ability of important loads. Summarizing the difficulties we need to overcome when put this technology into application. Pointing out a new way for disaster resilience research of important loads.
\end{abstract}

\section{Introduction}

In recent years, the rapid development of power system in china makes the continuous expand of network scale, power system interconnection becomes more and more closely. Meanwhile, with global climate change, electric power system is facing more and more various natural disasters challenges. From the data in Table 1, we can know that the rate of power outages caused by the natural disasters was up to $50 \%$, the natural disasters is the biggest risk source of power system blackouts.

\begin{tabular}{|c|c|c|c|c|c|c|c|c|c|c|c|c|}
\hline \multirow{3}{*}{$\begin{array}{c}\text { fault type } \\
\text { occur } \\
\text { time }\end{array}$} & \multicolumn{3}{|c|}{$\begin{array}{l}\text { Natural } \\
\text { disaster }\end{array}$} & \multicolumn{4}{|c|}{$\begin{array}{l}\text { Equipment } \\
\text { failure }\end{array}$} & \multicolumn{2}{|c|}{$\begin{array}{l}\text { Human } \\
\text { causes }\end{array}$} & \multirow[b]{2}{*}{$\mathrm{O}$} & \multirow[b]{2}{*}{$\begin{array}{c}\text { energy } \\
\text { Crisis }\end{array}$} & \multirow[b]{2}{*}{$\begin{array}{c}\text { Unknown } \\
\text { reason }\end{array}$} \\
\hline & $\mathrm{S}$ & TH & ТP & $\mathrm{O}$ & line & station & $\mathrm{O}$ & settings & $\begin{array}{l}\text { wrong } \\
\text { action }\end{array}$ & & & \\
\hline & 13 & 6 & 33 & 7 & 12 & 15 & 2 & 2 & 5 & 3 & 4 & 8 \\
\hline $\begin{array}{l}\text { category } \\
\text { rate }\end{array}$ & $\begin{array}{l}22 . \\
03\end{array}$ & $\begin{array}{l}10 . \\
17\end{array}$ & $\begin{array}{l}55 . \\
93\end{array}$ & $\begin{array}{l}11 . \\
36\end{array}$ & 11.80 & 51.72 & $\begin{array}{c}6.9 \\
0\end{array}$ & 20.00 & 50.00 & $\begin{array}{l}30 . \\
00\end{array}$ & 100 & 100 \\
\hline $\begin{array}{l}\text { total } \\
\text { rate }\end{array}$ & & & .64 & & & 26.36 & & & 9.09 & & 3.64 & 7.27 \\
\hline
\end{tabular}

Table 1 Statistics of blackouts reasons

In the Table 1: S represent snow, TP represent typhoon, TH represent thunder, O represent other.

Blackouts caused by the natural disasters have incalculable risks and effects on society. For example: traffic lights go out will result in urban traffic chaos and even lead to traffic gridlock; blackouts in hospital will stop surgery, resulting in the fatal accident; water supply system will lose power, resulting in a large area of the city lacking of water, and so on. Under the condition of disaster, ensuring the reliable power supply to important users have great significance to normal operation of the city.

Important power load is the main pillar of social economy development, is also the lifeline of the city. The important user in this paper is the importance users under disaster conditions, namely lifeline users. The so-called urban lifeline system refers to the essential support system in public daily life, is the important infrastructure to ensure the normal operation of urban life, also the foundation project to maintain the function of urban [1]. Once the important users power failure or disturbance, which will not only endanger public security and people's personal safety, but also will cause loss or significant impact on political or economics. Therefore, improving the disaster response capacity of the important user is of great significance. 


\section{Research status of the disaster response}

Important power users is the main pillar of social economy development, is also the lifeline of the city. Enhancing the resilience of critical loads under disaster conditions has a significance to urban normal operation. At present, the research of disaster response focused on the following aspects:

\section{Research on fast recovery algorithm of load after disaster}

After a natural disaster, power grids could face blackouts. Therefore, fast recovery of the loads for urban power grid has a great importance. Currently, there are several fault recovery algorithm, such as genetic algorithms, greedy algorithms, optimization algorithms, artificial neural networks and so on.

Genetic algorithm (GA) was first proposed by Professor John Holland in Michigan University. Genetic algorithm is based on the mechanism of natural selection and genetics, in accordance with the information required for solving the problem, then establish the algorithm. In paper [2], the genetic algorithm is applied to load recovery after blackout, and proposes to introduce the weighting factors in the power recovery rate, such as high priority load assigned high weight factor to reflect the importance of the load, then established the important load recovery algorithm. And received good results through examples.

Greedy algorithm is a hierarchical approach which can get the optimal solution in some sense. The paper [3] is based on the greedy algorithm, it considers from a key optimization measure, and combined with the requirements of actual system recovery, presents a recovery algorithm considering the important load have priority recovery.

The load recovery optimization problem is proposed in paper [4], the load recovery optimization problem consider as a high-dimensional 0-1 knapsack problem, the goal of this method is set the amount of load restoration maximum and give the priority to the important load in the case of remaining system network structure unchanged and meeting all operating constraints.

\section{Disaster response research based on smart grid}

Distributed Generation can produce many beneficial effects on the distribution network, also has an important role in promoting the disaster resilience of important load. For example: micro-grid containing distributed generation can maintain power supply of all or part of the important users in large power outage, it can avoid the serious consequences caused widespread power outages, once a disaster occurs, distributed generation can maintain some important loads and reduce disaster losses.

The paper [5] studied the power grid blackouts, and proposed use distributed generation islanding to maintain power supply of important load, in the maintenance of power supply of important load, put recovery of non-fault power outage area maximum, and combined with example verified.

In addition, some paper also puts forward equipped with a self-contained power supply for the important user, improve the disaster response capacity. Paper [6] analyses the present situation and the configuration significance of owned emergency power source for important user, then puts forward the equipment and management countermeasures of emergency power source, ensure that the owned power source play a key role in disaster time.

\section{Situation awareness}

The data from large-scale acquisition does not represent the information, the information does not represent knowledge of various indicators in power system. In some situations, chaotic data and information is a negative effect or even disasters for the operator [7]. In human decision-making, a process which contains the perception, understanding and prediction of the environment information is called situation awareness.

Elements perception: Get important clues or elements in the environment.

Elements comprehension: Integrating perceived data and information, analyzing its relevance.

Situation forecast: Based on the perception and understanding of environmental information to 
predict future trends, which is the highest level of situation awareness requirements.

As the American Scholar Dominguez introduced the concept of visualization, the definition of situation awareness has been shaped. The model is shown in Figure 1. It includes four parts: perception, comprehension, display and forecast.

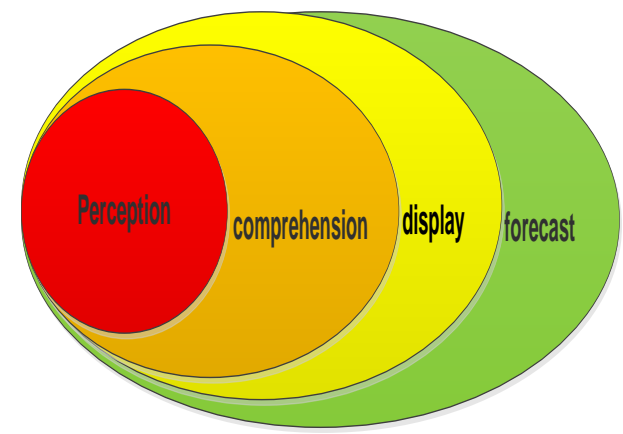

Figure 1 Situation awareness model

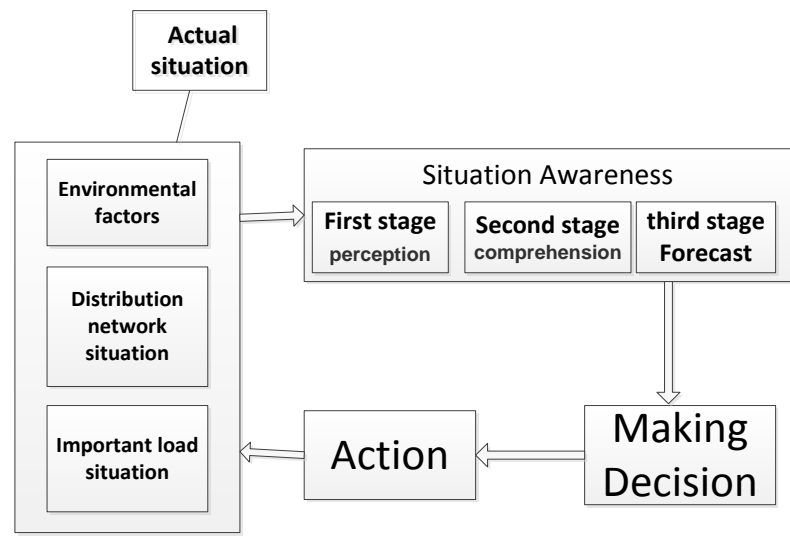

Figure 2 Situational awareness architecture

Situation awareness was first used in the space, military and other fields. Nowadays, the application in intelligent traffic system and computer network have gradually matured. In power system of foreign countries, they use the technologies which have successful applied in military and network security field, combined with the visualization and the advanced application function of the automation system, achieve a comprehensive intelligent decision support system which contains the perception, understanding and the forecasting.

\section{Research direction}

Currently, most disaster response plans of important users are passive repair mode after the disaster or provide reliable backup source to protect the important users. By study the situation awareness, we can get all current situation and put them into together. So, we can perceive the current state of the distribution network and to predict the future state. Meanwhile, we can also get the situation of important loads, put forward warning, then improve disaster response capacity. The situation awareness architecture of important user is shown in Figure 2. From the Figure 2, if we want to put this new method into practice, we need to overcome some difficulties as follows:

Study disaster situation model.

Since the goal of this paper is to enhance the disaster resilience of important users, therefore, we need to study the disaster situation models. First of all, from the view of information standardization and modeling ideas, discusses the model of the disaster and model of the disaster effect. Then, studying sub-situation of disaster effects on important user. At present, we have established several disasters impact models.

\section{1) The impact of ice thickness on the failure rate}

The fuzzy language variables $E_{B}$ represent input variables of ice thickness. The definition as follows:

$T_{B}=\{\leq 0.3 \mathrm{~B}$; about $0.5 \mathrm{~B}$; about 1.1B; about 1.5B; about 2.0B; about 2.5B; about $3.0 \mathrm{~B} ; \geq$ 4.0B\};

The definition of output variables as follows:

$E_{\lambda}=$ about 1 ; about $6 \times 10^{2}$; about $4 \times 10^{3}$; about $1 \times 10^{4}$; about $2 \times 10^{4}$; about $5 \times$ $\left.10^{4} ; \geq 1 \times 10^{5}\right\}$

In the type, $\mathrm{B}$ is designed ice thickness of lines, the input variable values have 8 values.

2) Substation component damage probability models

Damage index of a building under a seismic intensity:

$\mathrm{D}(\mathrm{I})=\sum_{j=1}^{5} P\left(d_{i} \mid I\right) d_{j}$

In the type, $P\left(d_{i} \mid I\right)$ is ratio of occurs $d_{j}$ grade damage in I intensity (general admission area 
ratio); $d_{j}$ is destruction index of the structure.

Therefore, the probability of damage to components under the seismic case:

$P_{i}=1-[1-D(I)]\left(1-P_{d i}\right)$

In the type, $\mathrm{D}(\mathrm{I})$ is damage index of components owned the buildings; $P_{d i}$ is the damage probability of electrical equipment components.

\section{Study situation model of the distribution network}

Firstly, we need to take research on the distribution network aware technology as the premise of the insufficient or poor data, where we need to study state estimate and virtual measurement technologies of distribution network under disaster conditions. Lastly, discussing distribution network model under the conditions of disaster, and setting up power supply situation model of distribution network under the disaster condition.

\section{Study situation model of important user}

Firstly, combined with the current load forecasting techniques, discussed load forecasting techniques of important user under disaster conditions. Secondly, because the important users are equipped with a backup power supply, therefore, we need to study the self-support ability of important user under disaster conditions. Lastly, taking a comprehensive discussion of load forecasting and the self-support ability of the important user, then establishing sub-situation model of important user.

\section{Study multi-dimensional situation synthesis technology}

Based on the above research, take a discussion on important loads vacancy situation model in consider with power supply capacity situation of distribution network and sub-situation model of important user, then establish the warning mechanism.

\section{Conclusion}

This paper analyzes the current disaster resilience studies of important user and situation awareness technology, proposes that situation awareness is applied to disaster resilience study of important users, then enhance the study of disaster warning, and enhance disaster resilience of important users.

\section{References}

[1] J. Li. Earthquake Resistant Engineering basic theory and application of Lifeline Project [M]. Beijing: Science Press, 2005

[2] M.J. Sun. Research and application in power supply restoration of distribution network [D]. Tianjin University. 2012

[3] H.B. Qu. Load restoration after blackout [D]. Chongqing University 2012

[4] S.Q. Zeng. Power system restoration optimization model and method after blackout [D]. South China University of Technology. 2011

[5] B.C. Zou. Algorithm for Distribution Network Reconfiguration and fault recovery in consider with Distributed Generation [D]. Wuhan University 2012

[6] Z.W. Lv. Analysis emergency power management of important user self supply [J] Demand Side Management. 2009, 11(1). 70-72

[7] ENDSLEY M R, CONNORS E S. Situation awareness: state of the art[C]//IEEE Power and Energy Society General Meeting: Conversion and Delivery of Electrical in the 21st Century, July 20-28, 2008, Pittsburgh, PA,USA:4P 